\title{
TINGKAT KERAWANAN KEBAKARAN HUTAN DAN LAHAN MENGGUNAKAN SISTEM INFORMASI GEOGRAFIS (SIG) DI KOTA AMBON (STUDI KASUS DI JAZIRAH LEITIMUR SELATAN)
}

\section{FOREST AND LAND FIRE VULNERABILITY LEVEL USE GEOGRAPHIC INFORMATION SYSTEM (GIS) IN AMBON (CASE STUDY IN JAZIRAH LEITIMUR SELATAN)}

Oleh

\author{
Aldi Herdian ${ }^{1)}$, Aryanto Boreel ${ }^{2)}$, Ronny Loppies ${ }^{3)}$ \\ ${ }^{1)}$ Mahasiswa Program Studi Kehutanan Universitas Pattimura, Ambon 97123 \\ ${ }^{2,3)}$ Dosen Program Studi Kehutanan Universitas Pattimura, Ambon 97123 \\ E-mail: aldiherdian96@gmail.com
}

\begin{tabular}{|l|l} 
Diterima: 2 Februari 2021 & Disetujui: 18 Maret 2021
\end{tabular}

\begin{abstract}
Abstrak
Terbatasnya data serta kurangnya pemanfaatan Teknologi Penginderaan Jauh dan Sistem Informasi Geografis (SIG) untuk memetakan daerah yang berpotensi rawan kebakaran hutan dan lahan di Kota Ambon merupakan salah satu penghambat dalam penanganan kebakaran hutan dan lahan. Penelitian ini bertujuan untuk mengidentifikasi faktorfaktor penyebab terjadinya kebakaran hutan dan lahan, menentukan tingkat kerawanan kebakaran hutan dan lahan serta menghasilkan peta digital kebakaran hutan dan lahan di Jazirah Leitimur Selatan Kota Ambon. Data yang digunakan adalah citra satelit Landsat 8 OLI/TIRS C1 Level-1 path/row 109/62 akuisisi 28 Oktober 2017. Data hotspot diperoleh dari FIRMS dan Lapan Fire Hotspot. Pengolahan data dilakukan dengan metode tumpang susun (overlay) variabel pemicu terjadinya kebakaran hutan dan lahan. Hasil penelitian menunjukkan bahwa Jazirah Leitimur Selatan berpotensi rawan kebakaran hutan dan lahan dengan 76,6\% areal termasuk dalam kategori rawan hingga sangat rawan, sedangkan $23,4 \%$ termasuk kategori tidak rawan.
\end{abstract}

Kata Kunci : SIG, Kerawanan, Landsat 8, Overlay, Hotspot

\section{Abstract}

Limited data and the lack of use of Remote Sensing Technology and Geographic Information Systems (GIS) to map areas that are potentially prone to forest and land fires in Ambon City are one of the obstacles in handling forest and land fires. This study aims to identify the factors that cause forest and land fires, determine the level of vulnerability to forest and land fires and produce a digital map of forest and land fires in Jazirah Leitimur Selatan, Ambon City. The data used are Landsat 8 OLI/TIRS C1 Level-1 path/row 109/62 satellite imagery acquired on October 28, 2017. Hotspot data was obtained from FIRMS and Lapan Fire Hotspot. Data processing is done by using the method of overlaying variables that trigger the occurrence of forest and land fires. The results showed that the Jazirah Leitimur Selatan has the potential to be prone to forest and land fires with $76.6 \%$ of the area included in the vulnerable to very vulnerable category, while $23.4 \%$ is in the non-prone category.

Keywords: GIS, Vulnerability, Landsat 8, Overlay, Hotspot 


\section{PENDAHULUAN}

Indonesia mempunyai luas hutan yang menempati urutan ketiga dunia setelah Brasil dan Zaire. Luas hutan Indonesia kini diperkirakan mencapai 125,9 juta $\mathrm{Ha}$, atau 63,7 persen luas daratan (KLHK, 2018). Secara internasional hutan Indonesia berfungsi sebagai paru-paru dunia dan dianggap signifikan mempengaruhi iklim dunia (Nurhayati, 2007 dalam Tubulele, 2014).

Tutupan lahan pada kawasan hutan bergerak sangat dinamis dan cenderung berubah dari tahun ke tahun menyebabkan kondisi hutan semakin menurun dan luas tutupannya berkurang. Beberapa kegiatan yang ditengarai sebagai penyebab pengurangan luas hutan adalah konversi kawasan hutan untuk tujuan pembangunan sektor lain, pengelolaan hutan yang tidak lestari, pencurian kayu dan penebangan liar, pertambangan, perambahan dan okupasi lahan serta kebakaran hutan (KLHK, 2018).

Kebakaran hutan dan lahan yang terjadi pada tahun 2015 merupakan salah satu kebakaran terbesar di Indonesia pasca kebakaran pada tahun 1997/1998. Tahun 2016 bahkan hingga pertengahan tahun 2017 peristiwa kebakaran hutan dan lahan di Indonesia terus terjadi. Dampak kebakaran telah menimbulkan potensi kerugian yang tidak bisa dihitung secara finansial berupa hilangnya keanekaragaman hayati, rusaknya habitat hidup satwa liar dan perubahan ekosistem dan lingkungan (Endrawati dkk, 2018). Selain itu mempengaruhi negara tetangga seperti Singapura, Malaysia, Thailand dan Filipina Selatan karena dampak penyebaran asap yang berasal dari kebakaran hutan dan lahan di Indonesia. Kejadian ini dinyatakan sebagai salah satu bencana lingkungan terburuk sepanjang abad (Glover, 2001 dalam Tacconi, 2003).

Dengan melihat dampak yang ditimbulkan akibat kebakaran hutan dan lahan, perlu dilakukan deteksi dini untuk melakukan tindakan pencegahan dan penanggulangan kebakaran hutan dan lahan. Salah satu metode pencegahan kebakaran hutan dan lahan yaitu early warning system yang dapat dilakukan dengan analisis data titik panas melalui penginderaan jarak jauh (Endrawati dkk, 2018). Adanya beberapa satelit yang mampu memantau titik-titik api (hotspot) seharusnya dapat membantu untuk melakukan mitigasi bencana kebakaran dengan melakukan pemetaan wilayah yang rawan kebakaran. Selain itu, kondisi iklim merupakan salah satu faktor pemicu terjadinya kebakaran hutan. Fenomena El-Nino menimbulkan perubahan iklim, antara lain musim panas yang berkepanjangan sehingga menimbulkan kekeringan. Oleh Karena itu, dengan memanfaatkan data-data fenomena iklim, maka tingkat terjadinya kebakaran dapat diminimalisir.

Kota Ambon merupakan kota yang beriklim hutan hujan tropis, serupa dengan iklim sebagian besar wilayah Indonesia dan Maluku Tengah. Iklim hutan hujan tropis Ambon dapat dilihat dari banyaknya hutan hujan tropika di kota yang sempat terbakar berkali-kali. Rata-rata suhu tertinggi yang terekam di kota ambon adalah $33,9^{\circ} \mathrm{C}$, sedangkan rata-rata terendah suhu terendahnya $25,1^{\circ} \mathrm{C}$ (BPS Kota Ambon, 2019). Curah hujan tertinggi di kota ambon adalah $809 \mathrm{~mm}$, sedangkan terendah adalah $78 \mathrm{~mm}$. Rata-rata suhu tertinggi dan curah hujan yang rendah di kota Ambon akan menyebabkan kerentanan terhadap kebakaran hutan dan lahan. Akibat dari kondisi suhu yang tinggi dan curah hujan yang rendah telah terjadi kebakaran hutan 
pada awal tahun 2020 ini, yang terjadi di Negari Rutong Kecamatan Leitimur Selatan yang telah menghanguskan kurang lebih 40 Ha. Untuk kebakaran di kawasan Air Besar Kelurahan Batu Merah yang terjadi di bulan pertama tahun 2020, hutan yang terbakar kurang lebih $20 \mathrm{Ha}$

Terbatasnya data serta kurangnya pemanfaatan Teknologi Penginderaan Jauh dan Sistem Informasi Geografis (SIG) untuk memetakan daerah yang berpotensi rawan kebakaran hutan dan lahan di Kota Ambon merupakan salah satu penghambat dalam penanganan kebakaran hutan dan lahan. Oleh karena itu, penelitian "Tingkat Kerawanan Kebakaran Hutan dan Lahan Menggunakan Sistem Informasi Geografis (SIG) di Jazirah Leitimur Selatan Kota Ambon" menjadi penting dilakukan.

Tujuan penelitian ini adalah mengidentifikasi faktor-faktor penyebab terjadinya kebakaran hutan dan lahan, menentukan tingkat kerawanan kebakaran hutan dan lahan serta menghasilkan peta digital kebakaran hutan dan lahan di Jazirah Leitimur Selatan Kota Ambon

\section{METODE PENELITIAN}

\section{Lokasi dan Waktu Penelitian}

Penelitian ini dilaksanakan di Jazirah Leitimur Selatan, selama bulan September 2019 - Januari 2020 .

- Koreksi Radiometrik; Koreksi radiometrik dilakukan karena hasil rekaman satelit mengalami kesalahan yang disebabkan oleh gangguan

\section{Tahap Pengolahan Citra}

- Pengolahan Awal Data Citra; Data Citra yang diperoleh dari situs www.glovis.usgs.gov masih

\section{Alat dan Bahan}

Peralatan yang digunakan dalam penelitian ini berupa seperangkat personal computer (PC) terinstal aplikasi ArcGIS 10.x, Envi dan Microsoft Office 2010, GPS dengan akurasi < 10 m, kamera dan alat tulis menulis. Bahan yang digunakan berupa antara lain Citra Landsat 8 OLI/TIRS CI Level-1 Path/Row 109/62 28 Okt 2017, Data Curah Hujan Tahun 2009-2018, Data tutupan lahan, Data suhu, Data Hotspot 2015-2020, Peta Administrasi Pulau Ambon.

\section{Pengolahan Citra}

\section{Tahap Pra Pengolahan}

- Koreksi Geometrik; Koreksi geometrik pada citra Landsat merupakan upaya memperbaiki kesalahan perekaman secara geometrik agar citra yang dihasilkan mempunyai sistem koordinat dan skala yang seragam, dan dilakukan dengan cara translasi, rotasi, atau pergeseran skala. Sebagai titik kontrol medan (koordinat acuan) untuk koreksi geometrik digunakan peta rupa bumi skala 1:25.000. Transformasi geometri yang paling mendasar dalam Arnanto (2013) adalah penempatan kembali posisi piksel sedemikian rupa, sehingga pada citra digital yang tertransformasi dapat dilihat gambaran obyek di permukaan bumi yang terekam sensor.

atmosfer. Gangguan atmosfer menyebabkan nilai pantulan yang diterima oleh sensor mengalami penyimpangan.

berupa data mentah, oleh karena itu perlu adanya proses yang berfungsi untuk mempersiapkan data tersebut agar dapat diolah dan kemudian dianalisis. 
Proses yang dimaksud meliputi komposit band (kanal), koreksi geometrik, mosaik band, dan pemotongan citra (cropping). Pemotongan citra

- Klasifikasi Lahan; Metode klasifikasi citra yang digunakan adalah klasifikasi terbimbing (supervised classification). Lillesand \& Kiefer (1990) mendefinisikan klasifikasi terbimbing sebagai proses pemilihan kategori informasi atau

- Pengolahan Data Hostpot; Pengolahan data hotspot yang diperoleh dari FIRMS dan Lapan Fire Hospot berupa data sebaran titik api (hotspot). Data hotspot ini diolah lanjut menggunakan Software ArcGIS untuk memperoleh peta kepadatan titik hotspot dalam mendukung pembuatan peta kerawanan berdasarkan data hotspot dan variabel

\section{Analisis Data}

Klasifikasi dan Skoring; dalam penelitian ini mengacu pada batas Jazirah Leitimur Selatan (Haumahu, 2014).

kelas yang diinginkan dan kemudian memilih daerah latihan (training area) yang mewakili tiap kategori. Citra yang digunakan untuk proses klasifikasi merupakan citra komposit dengan kombinasi band 432 .

lainnya. Pengolahan data hotspot menggunakan tools Kernel Density di dalam Spatial Analyst Tools.

\section{- Pengolahan Data Curah Hujan dan Suhu}

Permukaan; Data curah hujan dan suhu diolah dengan menggunakan Inverse Distance Weighted pada Spatial Analyst Tools.

Tahap ini, dilakukan skoring pada setiap indikator yang digunakan sesuai Tabel 1.

Tabel 1. Klasifikasi Skoring Indikator Kebakaran Hutan dan Lahan

\begin{tabular}{|c|c|c|c|c|}
\hline Variabel & Karakteristik & Skor & Kelas Kerawanan & Sumber \\
\hline \multirow{5}{*}{ Curah Hujan } & $>4000$ & 1 & Sangat Rawan & \multirow{5}{*}{$\begin{array}{c}\text { (Rosdiana, 2017) } \\
\text { dimodifikasi }\end{array}$} \\
\hline & $3000-4000$ & 2 & Rawan & \\
\hline & $2000-3000$ & 3 & Sedang & \\
\hline & $1000-2000$ & 4 & Tidak Rawan & \\
\hline & $<1000$ & 5 & Sangat Tidak Rawan & \\
\hline \multirow{5}{*}{ Suhu } & Suhu $>30^{\circ} \mathrm{C}$ & 1 & Sangat Rawan & \multirow{5}{*}{$\begin{array}{c}\text { (Putri Amalia, } \\
\text { 2015) }\end{array}$} \\
\hline & $25-30^{\circ} \mathrm{C}$ & 2 & Rawan & \\
\hline & $20-25^{\circ} \mathrm{C}$ & 3 & Sedang & \\
\hline & $15-20^{\circ} \mathrm{C}$ & 4 & Tidak Rawan & \\
\hline & Suhu $<15^{\circ} \mathrm{C}$ & 5 & Sangat Tidak Rawan & \\
\hline \multirow{5}{*}{ Hotspot } & $<10$ & 1 & Sangat Tidak Rawan & \multirow{5}{*}{$\begin{array}{l}\text { (Rosdiana, 2017) } \\
\text { dimodifikasi }\end{array}$} \\
\hline & $10-20$ & 2 & $\begin{array}{l}\text { Tidak Rawan } \\
\text { nan }\end{array}$ & \\
\hline & $30-40$ & 3 & Sedang & \\
\hline & $40-50$ & 4 & Rawan & \\
\hline & $>50$ & 5 & Sangat Rawan & \\
\hline \multirow{5}{*}{ Tutupan lahan } & $\begin{array}{l}\text { Alang- } \\
\text { alang/semak }\end{array}$ & 1 & Sangat Rawan & \multirow{5}{*}{$\begin{array}{c}\text { (Putri Amalia, } \\
\text { 2015) }\end{array}$} \\
\hline & Lahan terbuka & 2 & Rawan & \\
\hline & Pemukiman & 3 & Sedang & \\
\hline & Hutan Sekunder & 4 & Tidak Rawan & \\
\hline & Hutan Primer & $\begin{array}{l}4 \\
5\end{array}$ & Sangat Tidak Rawan & \\
\hline
\end{tabular}

Pembobotan; Tahap pembobotan dilakukan untuk menentukan pengaruh indikator yang digunakan terhadap analisis yang dilakukan. Pembobotan ini dilakukan dengan melihat bagaimana pengaruh curah hujan, suhu permukaan tanah, tutupan lahan dan hotspot terhadap terjadinya kebakaran hutan dan lahan.

Analisis Kerawanan; Nilai kerawanan diperoleh dengan metode tumpang susun semua peta variabel, maka akan muncul peta baru yang menunjukkan tingkat kerawanan terjadinya kebakaran hutan dan lahan di Jazirah Leitimur Selatan. Hasil yang muncul berdasarkan pada hasil skor kumulatif yang diperoleh dari keseluruhan parameter dengan formula sebagai berikut (Rosdiana, 2017):

$$
\mathrm{K}=\left[\left(0,063^{*} \mathrm{CH}\right)+(0,067 * \mathrm{SPT})+(0,240 * \mathrm{PL})+(0,630 * \mathrm{H})\right]
$$


Dimana $\mathrm{K}$ merupakan nilai kerawanan, $\mathrm{CH}$ merupakan Curah Hujan, SPT merupakan Suhu Permukaan Tanah, PL merupakan Penutupan

\section{HASIL DAN PEMBAHASAN}

Pra-Pengolahan Citra Satelit

\section{- Koreksi Geometrik}

Kualitas hasil koreksi geometrik dilihat dengan pemilihan 32 titik GCP (Ground Check

Tabel 2. Uji Ketelitian Koreksi Geometrik Titik-titik GCP

\begin{tabular}{cc}
\hline Citra Tahun & Nilai RMSE \\
\hline 2017 & 0.003820 \\
\hline Sumber: Hasil Analisis SIG &
\end{tabular}

Hasil koreksi geometrik merupakan penyesuaian proyeksi citra dengan koordinat bumi.

\section{- Koreksi Radiometrik}

Koreksi radiometrik merujuk pada operasi untuk mengurangi atau menghilangkan distorsi radiasi elektromagnetik yang diterima oleh tiap detektor. Prosedur koreksi radiometrik perlu memperhatikan karakteristik dari distorsi. Koreksi radiometrik diperlukan untuk variasi dari tingkat iluminasi suatu scene dan geometrik penglihatan (viewing geometry) kondisi atmosfer, noise dan respons sensor. Koreksi radiometrik dipengaruhi

\section{- Pemotongan Citra}

Pemotongan citra yang dilakukan pada Citra Pulau Ambon, terlebih khusus wilayah Jazirah Leitimur Selatan. Pemotongan ini dilakukan untuk
Lahan, H merupakan Hotspot dan S merupakan Nilai Pembobotan setiap indikator yang digunakan.

Point). Hasil uji ketelitian dapat dilihat pada Tabel 2. 


\section{Pengolahan Citra Satelit}

\section{- Klasifikasi Citra}

Klasifikasi terhadap citra dilakukan sesuai kelas penutupan lahan dengan mengacu pada Perdirjen Planologi Kehutanan Nomor P.1/VIIIPSDH/2015 tentang pendoman pemantauan penutupan lahan berupa; hutan lahan kering primer, hutan lahan kering sekunder, semak belukar, pemukiman dan lahan terbuka. Pada tahapan ini di buat Training Sampel Area (TSA) pada wilayah studi penelitian yang bertujuan untuk mengidentifikasi objek yang tampak pada saat interpretasi citra dengan TSA yang dibangun berdasarkan luas penutupan lahan pada daerah Jazirah Leitimur Selatan sejumlah 100 sampel (Tabel 2). Metode yang dipakai dalam melakukan klasifikasi terbimbing adalah Maximum Likelihood Classification (MLC). Metode ini mempertimbangkan nila rata-rata dan keragaman antar kelas dan band (kovariansi).

Tabel 2. Training Sampel Area

\begin{tabular}{llc}
\hline No & \multicolumn{1}{c}{ Jenis Tutupan Lahan } & Jumlah Sampel \\
\hline 1. & Hutan Primer & 30 \\
2. & Hutan Sekunder & 33 \\
3. & Semak Belukar & 7 \\
4. & Lahan Terbuka & 2 \\
5. & Pemukiman & 28 \\
\hline \multicolumn{2}{c}{ Total }
\end{tabular}

Tabel 2, menjelaskan variasi jumlah sampel yang diambil pada tiap kelas penutupan lahan di lokasi penelitian. Jumlah sampel terbanyak pada kelas hutan sekunder sebanyak 33 sampel dan jumlah sampel yang sedikit ada pada kelas lahan terbuka sebanyak 2 sampel.

Dari hasil reklasifikasi citra landsat 8 untuk menentukan sebaran kelas penutupan lahan di

\begin{tabular}{ccccccc}
\hline & \multicolumn{7}{c}{ Terhitung (estimasi) } \\
\cline { 2 - 8 } & Hp & Hs & $\mathbf{P m}$ & $\mathbf{B}$ & $\mathbf{T}$ & $\begin{array}{c}\text { Jmlh } \\
\text { Baris }\end{array}$ \\
\hline $\begin{array}{c}\text { Hutan Lahan Kering Primer } \\
(\text { Hp) }\end{array}$ & $\mathbf{2 6}$ & $\mathbf{0}$ & $\mathbf{0}$ & $\mathbf{0}$ & $\mathbf{0}$ & $\mathbf{2 6}$ \\
\hline $\begin{array}{c}\text { Hutan Lahan Kering Skunder } \\
(\mathbf{H s})\end{array}$ & $\mathbf{4}$ & $\mathbf{3 0}$ & $\mathbf{0}$ & $\mathbf{0}$ & $\mathbf{0}$ & $\mathbf{3 4}$ \\
\hline Pemukiman (Pm) & $\mathbf{0}$ & $\mathbf{1}$ & $\mathbf{2 6}$ & $\mathbf{0}$ & $\mathbf{0}$ & $\mathbf{2 7}$ \\
\hline Semak Belukar (B) & $\mathbf{0}$ & $\mathbf{2}$ & $\mathbf{0}$ & $\mathbf{6}$ & $\mathbf{0}$ & $\mathbf{8}$ \\
\hline Sahan Terbuka (T) & $\mathbf{0}$ & $\mathbf{0}$ & $\mathbf{2}$ & $\mathbf{1}$ & $\mathbf{2}$ & $\mathbf{5}$ \\
\hline Jmlh Kolom & $\mathbf{3 0}$ & $\mathbf{3 3}$ & $\mathbf{2 8}$ & $\mathbf{7}$ & $\mathbf{2}$ & $\mathbf{1 0 0}$ \\
\hline
\end{tabular}

Dari hasil analisis pada Tabel, menunjukkan bahwa kelimat (5) kelas penutupan yang memberi sumbangan ke tiap-tiap sampel yang berbeda, diantaranya (Hp) sebesar 4 sampel ke (Hs), (Hs) ke lokasi penelitian diperoleh 5 (lima) kelas penutupan lahan yaitu hutan primer, hutan sekunder, semak belukar, lahan terbuka, pemukiman. Hasil klasifikasi ini, selanjutnya diuji keakuratannya menggunakan matriks kesalahan yang membandingkan hasil reklasifikasi dengan hasil pengecekkan lapangan (ground truthing).

Tabel 3. Matriks Kesalahan (Confussion Matrix) Penutupan Lahan di Lokasi Penelitian

$(\mathrm{Pm})$ sebesar 1 dan ke $(\mathrm{B})$ sebesar 2, $(\mathrm{Pm})$ ke $(\mathrm{T})$ sebesar 2, (B) ke (T) sebesar 1, (T) tetap.

Berdasarkan perhitungan, uji ketelitian yang dilakukan untuk akurasi keseluruhan (overall accuracy) dari matriks sebesar 91\%, sedangkan 
untuk perhitungan coefisien kappa, akurasi yang di dapat sebesar 87,88\%. Dari nilai uji ketelitian ini, maka hasil klasifikasi termasuk dalam kategori "Baik”, Menurut (Jaya, 2009) menyatakan bahwa nilai akurasi yang baik adalah nilai yang telah mencapai skor $>85 \%$. Berikut disajikan penutupan lahan di lokasi penelitian (Tabel 4).

Tabel 4. Penutupan Lahan di Jazirah Leitimur Selatan

\begin{tabular}{lcc}
\hline \multicolumn{1}{c}{ Klasifikasi } & Luas (Ha) & Presentase (\%) \\
\hline Hutan Lahan Kering Primer & $4.540,88$ & $29,66 \%$ \\
\hline Hutan Lahan Kering Sekunder & $5.190,16$ & $33,90 \%$ \\
\hline Lahan Terbuka & $1.59,65$ & $1,04 \%$ \\
\hline Semak Belukar & $1.148,53$ & $7,50 \%$ \\
\hline Pemukiman & $4.267,45$ & $27,87 \%$ \\
\hline Total & $\mathbf{1 5 . 3 0 6 . 6 9 7}$ & $\mathbf{1 0 0 \%}$ \\
\hline Sumber : (Hasil Analisis.) 2019 & &
\end{tabular}

Hasil analisis sebagaimana terlihat pada Tabel 4, menjelaskan bahwa persentase luas tutupan lahan tertinggi pada kelas penutupan hutan lahan kering sekunder sebesar 33,90\% atau seluas 5190, $65 \mathrm{Ha}$, diikuti dengan kelas penutupan lahan hutan lahan

\section{Identifikasi Faktor-Faktor Penyebab Kebakaran Hutan dan Lahan}

\section{- Curah Hujan}

Berdasarkan data BMKG Ambon tahun 2009-2018, wilayah Jazirah Leitimur Selatan mempunyai curah hujan tertinggi dalam 10 tahun kering primer sebesar 29,66\% dengan luas 4540.88 Ha. Kelas penutupan lahan lahan terbuka mempunyai persentase luas tutupan terendah yaitu $1,04 \%$ atau luas $159.65 \mathrm{Ha}$.

terakhir terjadi pada bulan Juli sebesar $884 \mathrm{~mm}$ dan terendah pada bulan November sebesar $78 \mathrm{~mm}$ dengan rata-rata curah hujan bulanan sebesar dengan rata-rata curah hujan tahunan sebesar $327,750 \mathrm{~mm}$. Selanjutnya data curah hujan di lokasi studi setelah diklasifikasi ada pada kelas ke-5 (lima) dengan karakteristik curah hujan $>4000$ mm/tahun.

Tabel 5. Klasifikasi dan Skor Curah Hujan di lokasi Penelitian

\begin{tabular}{clll}
\hline Variabel & Karakteristik & Skor & Bobot \\
\hline \multirow{4}{*}{ Curah hujan } & $<1000$ & 1 & \\
\cline { 2 - 3 } & $1000-2000$ & 2 & \\
\cline { 2 - 3 } & $2000-3000$ & 3 & \\
\cline { 2 - 3 } & $3000-4000$ & 4 & 5 \\
\cline { 2 - 3 } & $>4000$ & \multicolumn{2}{c}{5} \\
\hline
\end{tabular}

Sumber: Data Sekunder setelah diolah (2019)

Dari hasil analisis tersebut dapat diketahui tingginya potensi kebakaran hutan diakibatkan oleh curah hujan yang rendah karena dapat mengurangi kandungan air pada kawasan hutan sehingga bahan bakar yang terbentuk dari vegetasi hutan mudah mengering dengan baik (Rosdiana, 2017). 


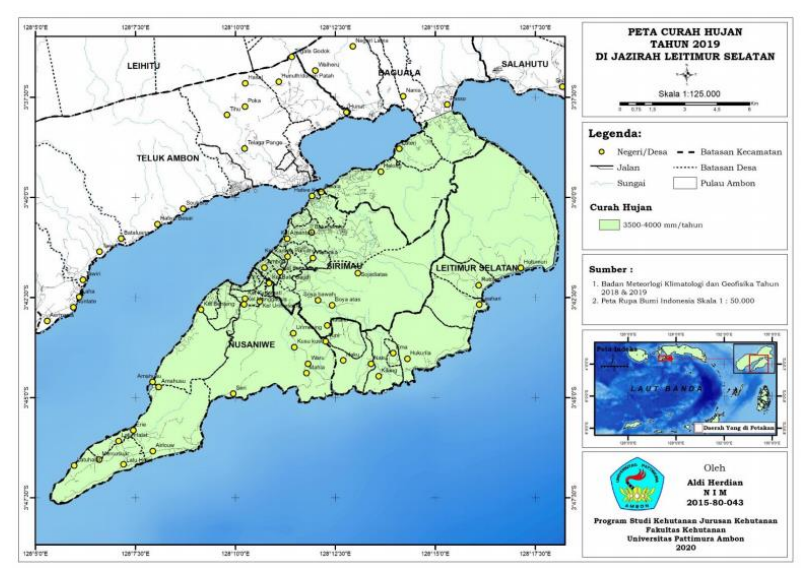

Gambar 2. Peta Curah Hujan di Lokasi Penelitian

\section{- Suhu Permukaan}

Suhu permukaan di Jazirah Leitimur Selatan berkisar anatara $30^{\circ} \mathrm{C}$ sampai $34^{\circ} \mathrm{C}$. Kota Ambon merupakan kota dengan suhu tinggi yang dapat di indikasikan termasuk daerah yang rawan terhadap terjadinya kebakaran hutan dan lahan. Suhu di atas $35^{\circ} \mathrm{C}$ diindikasikan sangat rawan terjadinya kebakaran hutan dan lahan

Tabel 6. Klasifikasi Suhu Permukaan

\begin{tabular}{llll}
\hline Variabel & Karakteristik & Skor & Bobot \\
\hline \multirow{4}{*}{ Suhu } & Suhu $>30^{\circ} \mathrm{C}$ & 1 \\
\cline { 2 - 3 } & $25-30^{\circ} \mathrm{C}$ & 2 \\
\cline { 2 - 3 } & $20-25^{\circ} \mathrm{C}$ & 3 \\
\cline { 2 - 3 } & $15-20^{\circ} \mathrm{C}$ & 4 \\
\cline { 2 - 3 } & Suhu $<15{ }^{\circ} \mathrm{C}$ & 5 \\
\hline
\end{tabular}

Sumber: Data Primer Setelah diolah (2020)

Dari hasi analisis spasial terlihat bahwa pada wilayah Jazirah leitimur termasuk dalam skor ke-1 (satu) dengan karakteristik >30 0C. Untuk itu dapat dianalisis bahwa pada lokasi penelitian memiliki intensitas suhu permukaan sangat tinggi, yang dapat memicu terjadinya kebakaran hutan dan lahan.

Suhu udara merupakan faktor yang selalu berubah bergantung pada intensitas radiasi surya dan mempengaruhi suhu bahan bakar serta kemudahannya terbakar (Chandler et. al., 1983). Khususnya daerah Ambon yang mempunyai suhu tinggi akan mempercepat terjadinya pengeringan bahan bakar dan memudahkan terjadinya kebakaran terutama jika terjadi pada musim kemarau panjang. 


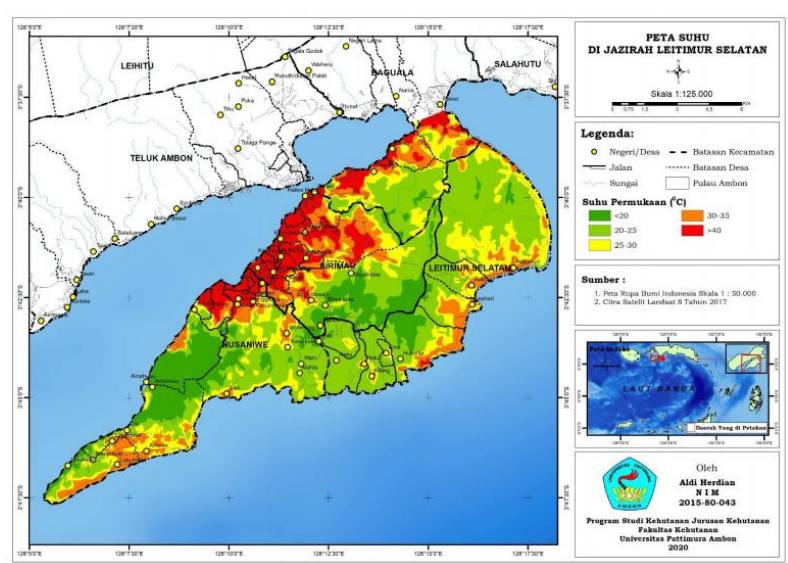

Gambar 3. Peta Suhu Permukaan di Lokasi Studi

\section{- Titik Api (Hotspot)}

Sebaran titik api (hotspot) pada lokasi penelitian Jazirah Leitimur Selatan dengan dengan jumlah titik sebanyak 41 titik yang tersebar di beberapa wilayah. Hasil klasifikasi menunjukkan bahwa sebaran titik api (hotspot) pada lokasi penelitian Jazirah Leitimur Selatan berada pada skor 4 (empat) dengan karakteristik 40-50.

Tabel 7. Klasifikasi Titik Api (Hotspot) di Lokasi Penelitian

\begin{tabular}{llll}
\hline Variabel & Karakteristik & Skor & Bobot \\
\hline \multirow{3}{*}{ Hotspot } & $<10$ & 1 & \\
\cline { 2 - 3 } & $10-20$ & 2 & \multirow{2}{*}{0,630} \\
\cline { 2 - 3 } & $30-40$ & 3 & \\
\cline { 2 - 3 } & $40-50$ & \multicolumn{2}{c}{5} \\
\cline { 2 - 3 } & $>50$ & \multicolumn{2}{c}{} \\
\hline
\end{tabular}

Sebaran titik api (hotspot) pada wilayah Jazirah Leitimur Selatan dari periode 5 tahun terakhir (2015-2020) dengan jumlah total titik api (hotspot) sebanyak 41 dengan total kepercayaan dari seluruh sebaran titik api (hotspot) sebesar 25.5\%.

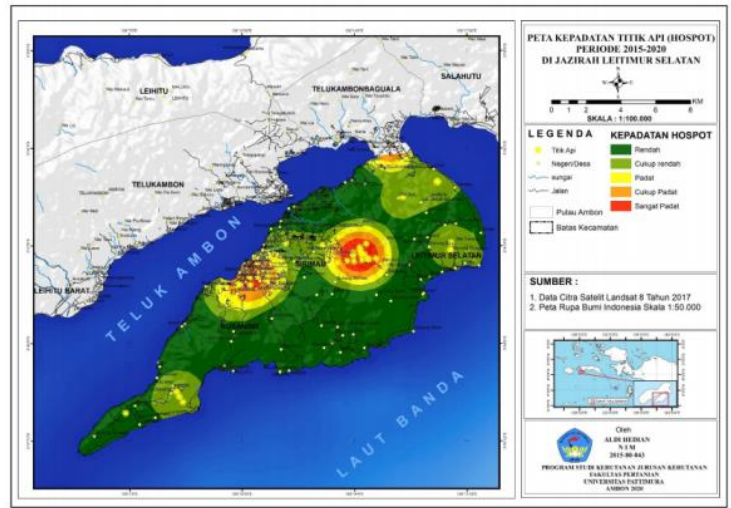

Gambar 4. Peta Kepadatan Titik Api (Hotspot)

Titik panas yang digunakan sebagai indikator kebakaran hutan dan lahan di suatu wilayah tidak hanya dapat disebabkan karena jumlahnya berulang, bergerombol namun juga selang kepercayaan titik

\section{- Penutupan Lahan}

Keadaan penutupan lahan di lokasi penelitian terdiri atas kelas hutan lahan kering panas tersebut. Semakin tinggi selang kepercayaan, maka semakin tinggi pula potensi bahwa hotspot tersebut adalah benar-benar kebakaran lahan atau hutan yang terjadi (LAPAN, 2016).

primer, hutan lahan kering sekunder, pemukiman, semak belukar, lahan terbuka (Tabel 8). 
Tabel 8. Klasifikasi Tutupan di Lokasi Studi

\begin{tabular}{lcc}
\hline \multicolumn{1}{c}{ klasifikasi } & Luas (Ha) & Presentase (\%) \\
\hline Hutan Lahan Kering Primer & 4540,88 & $29,66 \%$ \\
\hline Hutan Lahan Kering Sekunder & 5190,16 & $33,90 \%$ \\
\hline Lahan Terbuka & 159,65 & $1,04 \%$ \\
\hline Semak Belukar & 1148,53 & $7,50 \%$ \\
\hline Pemukiman & 4267,45 & $27,87 \%$ \\
\hline Total & $\mathbf{1 5 . 3 0 6 . 6 9}$ & $\mathbf{1 0 0} \%$ \\
\hline Sumber : hasil analisis, 2020 & &
\end{tabular}

Tabel 8, menunjukkan bahwa tutupan lahan luasan terkecil yaitu lahan terbuka $159,65 \mathrm{Ha}$ atau yang dominan di Jazirah Leitimur Selatan adalah 1,04\% dari seluruh kawasan Jazirah Leitimur hutan lahan kering sekunder dengan luas 5.190,16 Selatan.

Ha atau 33,90\%, kemudian tutupan lahan dengan

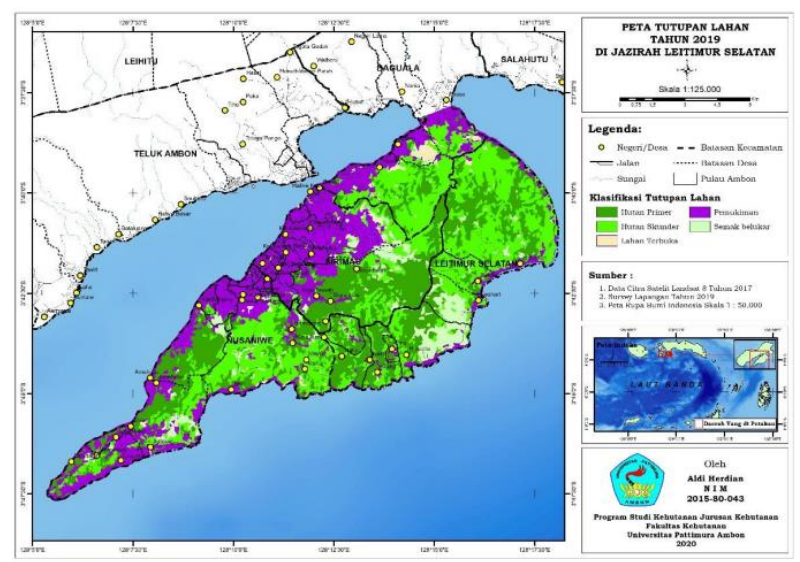

Gambar 5. Peta Penutupan Lahan Jazirah Leitimur Selatan

Perubahan jenis tutupan lahan secara nyata mengambil bagian penting dalam mengontrol indeks kerentanan kebakaran lahan dan hutan satu kawasan (Christiawan, 2018). Sehingga perubahan

\section{Pemodelan Kerawanan Kebakaran Hutan Dan} Lahan

Tahap awal pemodelan kerawanan adalah mendesain bobot masing-masing parameter yang digunakan yaitu curah hujan, suhu permukaan, hotspot, tutupan lahan untuk menentukan nilai jenis tutupan lahan yang cenderung lebih dinamis dari suatu sistem lahan dapat menentukan tingkat kerentanan kebakaran lahan tersebut (Vivitanti dkk, 2019).

kerawanan kebakaran hutan dan lahan. Dalam hal ini telah ditentukan nilai bobot dari berbagai variabel yang digunakan dalam menentukan nilai kerawanan kebakaran hutan dan lahan di Jazirah Leitimur Selatan.

Tabel 9. Bobot Setiap Parameter Dalam Menentukan Nilai Kerawanan Kebakaran Hutan Dan Lahan di Jazirah Leitimur Selatan.

\begin{tabular}{|c|c|c|}
\hline No & Parameter & Bobot \\
\hline 1 & Curah Hujan & 0.063 \\
\hline 2 & Suhu & 0.067 \\
\hline 3 & Hotspot & 0.630 \\
\hline 4 & Tutupan Lahan & 0.240 \\
\hline
\end{tabular}

Tahap analisis menghasilkan peta hasil sehingga akan tampil peta baru yang menunjukkan pemrosesan awal dari setiap parameter di overlay tingkat kerawanan kebakaran hutan dan lahan di 
Jazirah Leitimur Selatan., seperti tersaji dalam Tabel 10.

Tabel 10. Klasifikasi Kerawanan Kebakaran Hutan dan Lahan di Jazirah Leitimur Selatan

\begin{tabular}{ccc}
\hline No & Jumlah Skor & Kelas Kerawan \\
\hline 1 & $106.30-185.00$ & Sangat Tidak Rawan \\
\hline 2 & $185.00-248.00$ & Tidak Rawan \\
\hline 3 & $248.00-317.70$ & Rawan \\
\hline 4 & $317.70-391.30$ & Cukup Rawan \\
\hline 5 & $>391.30$ & Sangat Rawan \\
\hline Sumber: Analisis data, 2020 &
\end{tabular}

Hasil analisis permodelan spasial tingkat dapat dihasilkan suatu peta rawan kebakaran hutan dan lahan di lokasi penelitian.

kerawanan yang dibangun dari masing-masing variabel kerawanan kebakaran hutan dan lahan

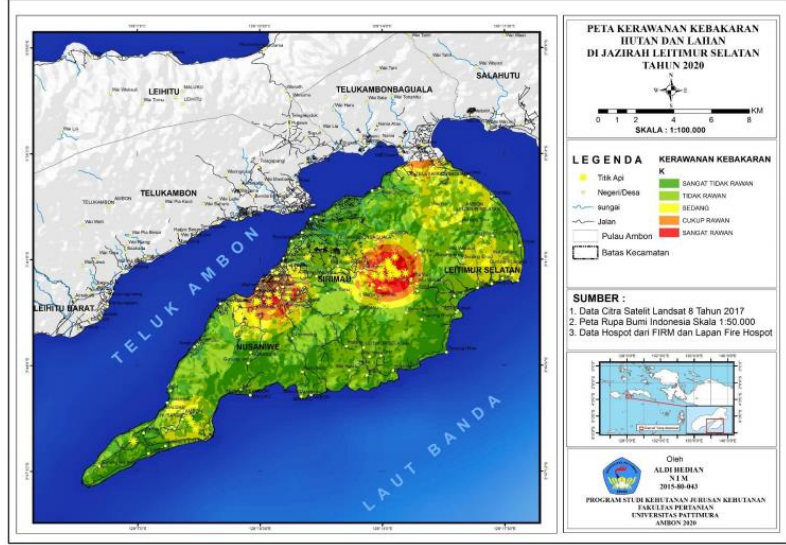

Gambar 6. Peta Kerawanan Kebakaran Hutan dan Lahan Di Jazirah Leitimur Selatan

Hasil penelitian menunjukan bahwa tingkat kerawanan kebakaran hutan di pengaruhi oleh lima parameter yakni curah hujan, suhu permukaan, hotspot, dan tutupan lahan. Masing-masing parameter mempunyai pengaruh yang dominan terhadap kebakaran.

Tingkat kerawanan di lokasi studi dapat diketahui untuk kelas kerawanan dengan kelas rawan yang sangat tinggi yaitu sangat rawan dengan luas $6.054,76$ ha (39.9\%), kemudian dengan tingkat kerawanan sangat tidak rawan dengan luasan terkecil yaitu sebesar $1.638,75$ ha $(10.8 \%)$.

Tingkat kerawanan di lokasi studi dipicu dari pengaruh sebaran titik api (hotspot) yang tinggi kemudian curah hujan yang rendah yang mengakibatkan naiknya suhu permukaan yang menyebabkan timbulnya kebakaran. Jumlah (hotspot) menjadi penentu utama peningkatan kebakaran hutan dan kebakaran hutan. Peningkatan jumlah (hotspot) signifikan meningkatkan luas areal kebakaran hutan

Curah hujan merupakan unsur iklim yang memiliki korelasi yang tinggi dengan kejadian kebakaran hutan (Soares dan Sampaio, 2000) dan merupakan faktor yang paling penting dalam menentukan akumulasi bahan bakar rerumputan (Wilgen et al, 1990). Musim kebakaran hutan biasanya berhubungan dengan pola curah hujan, terutama dengan kekeringan. Puncak musim kebakaran terjadi pada musim kemarau. Menurut Chandler et al. (1983), suhu udara merupakan salah satu indikator dari kondisi bahan bakar hutan karena suhu udara mempengaruhi kepekaan bahan bakar untuk menyala dan kecepatan pembakaran. Suhu 
bahan bakar dipengaruhi oleh penyerapan radiasi matahari secara langsung dan konduksi dari lingkungan sekitar. Selain itu ada pengaruh manusia yang menyebabkan terjadinya kebakaran hutan dan

\section{KESIMPULAN DAN SARAN}

\section{Kesimpulan}

1) Faktor-faktor pemicu peristiwa kebakaran hutan dan lahan di Jazirah Leitimur Selatan dipengaruhi oleh beberapa variabel yaitu curah

\section{Saran}

1) Pemerintah Kota Ambon perlu mengontrol setiap saat terutama pada musim kemarau yang menjadi indikasi terjadinya kebakaran hutan, agar mencegah hilangnya kawasan hutan akibat kebakaran hutan dan lahan.

\section{DAFTAR PUSTAKA}

Arnanto, A. 2013. Pemanfaatan Transformasi Normalized Difference Vegetation Index (NDVI) Citra Landsat TM Untuk Zonasi Vegetasi Di Lereng Merapi Bagian Selatan. Laboratorium SIG. Sekolah Tinggi Pertahanan Nasional. Yogyakarta.

[BPS] Badan Pusat Statistik. 2019. Kota Ambon Dalam Angka.

Chandler, C., P. Cheney, P. Thomas, L. Trabaud, D. William, 1983a. Fire and foresty Vol. I. John Wiley and sons. Canada. $450 \mathrm{pp}$.

Christiawan, P. I. (2018). Cultural Landscape : A Bridge Between Deforestation And Local Community ? Journal of Landscape Ecology, 11(2), 77-87. https://doi.org/10.2478/jlecol2018-0008

Endrawati, J Purwanto, S. Nugroho, R. A. S. 2018. Identifikasi Areal Bekas Kebakaran Hutan Dan Lahan Menggunakan Analisis Semi Otomatis Citra Satelit Landsat. Seminar Nasional Geomatika: Inovasi Teknologi Penyediaan Informasi Geospasial untuk Pembangunan Berkelanjutan lahan antara lain dikarekanakan adanya pembukaan lahan, alih fungsi lahan dan kelalaian dalam membuang puntung rokok yang akhirnya dapat memicu terjadinya kebakarna hutan dan lahan.

hujan, suhu, sebaran titik api (hotspot), penutupan lahan.

2) Tingkat kerawanan Jazirah Leitimur Selatan termasuk kategori sangat tinggi dengan luas $(39.9 \%)$.

2) Perlu adanya kesadaran bersama untuk menjaga lingkungan karena selain faktor alam, kebakaran pun kebanyakan terjadi oleh faktor manusia itu sendiri yang lalai atas perbuatannya, yang menyebabkan terjadinya kebakaran.

Haumahu, J. P. 2014. Analisis Perubahan Penggunaan Lahan Di Jazirah Leitimur Selatan Pulau Ambon. Program Studi Agroetoknologi, Jurusan Budidaya Pertanian. Universitas Pattimura. Ambon.

Indarto. 2017. Penginderaan Jauh Metode Analisis \& Interpretasi Citra Satelit. Sigit S, Andi. Yogyakarta.

Jaya INS. 2009. Analisis Citra Digital: Perspektif Penginderaan Jauh Untuk Pengelolaan Sumberdaya Alam. Bogor (ID): Fakultas Kehutanan IPB.

KLHK. 2018. Statistik Kementrian Lingkungan Hidup dan Kehutanan Indonesia tahun 2017, Jakarta, Kementrian Lingkungan Hidup dan Kehutanan RI

LAPAN (Lembaga Penerbangan dan Antariksa Nasional). (2016). Informasi Titik Panas (Hotspot) Kebakaran Hutan/Lahan. Pusat Pemanfaatan Penginderaan Jauh - Lapan. Jakarta.

Lillesand and Kiefer. 1990. Penginderaan Jauh dan Interpretasi Citra. Diterjemahkan oleh Dulbahri, Hartono, dkk. Fakultas Geografi. Universitas Gadjah Mada. Yogyakarta 
Prahasta, Eddy. 2009. Sistem Informasi Geografis: Konsep-konsep Dasar (Perspektif Geodesi \& Geomatika). Bandung: Penerbit Informatika.

Rosdiana. 2017. Analisis Kerawanan Kebakaran Hutan Menggunakan Metode MCDM (Multi Criteria Decision Making) Berbasis Geospasial. Provinsi Sumatra. Universitas Hasanuddin Makasar.

Soares, R. V. and O. B. Sampaio. 2000a. Widlfire occurrence in a forest district and other Brazilian protected areas. In Proccedings of Forest and Society: the Role of Research. Poster Abstrack Voll. III. XXI IUFRO Word Congress. Kuala Lumpur 7-12 August 2000. Malaysian XXI IUFRO Word Congress Organizing Committee. Malaysia. P. 498.

Tacconi, L. 2003. Fires in Indonesia: causes, costs and policy implications. CIFOR Occasional Paper No. 38. CIFOR, Bogor, Indonesia.
Tubulele, 2014. Kebakaran Hutan di Indonesia dan Proses Penegakan Hukumnya Sebagai Komitmen dalam Mengatasi Dampak Perubahan Iklim, diakses pada tanggal 10 Februari 2020 , https://www.aifisdigilib.org/uploads/1/2/3/4/6 /13465004/8_popi_kebakaran _hutan_indonesia.pdf

Viviyanti R. T. A. Adila, R. Rahmad. 2019. Aplikasi SIG untuk Pemetaan Bahaya Kebakaran Hutan dan Lahan di Kota Dumai. Media Komunikas Geografi Vol. 20, No.2, Desember 2019 (78 - 89).

Wilgen B. W. Van, K.B. Higgins, D.U. Bellstedt. 1990. The Role Of Vegetation Structure And Fuel Chemistry In Excluding Fire From Forest Patches In The Fire-Prone Fynbos Shrublands Of South Africa 